4. Sun HR, Tang H, Song HB. Ball thrombus in the right atrium after patch closure of atrial septal defect. Heart Lung Circ. 2014;23:e152-3.

5. Warnes CA, Williams RG, Bashore TM, Child JS, Connolly HM, Dearani JA, et al. ACC/AHA 2008 guidelines for the management of adults with congenital heart disease: a report of the American College of Cardiology/American Heart Association Task Force on Practice Guidelines (writing committee to develop guidelines on the management of adults with congenital heart disease). Circulation. 2008;118:e714-833.

\title{
Cor triatriatum dexter: A rare cause of myocardial infarction and pulmonary embolism in a young adult
}

\author{
Syed T. Hussain, MD, Kwabena Mawulawde, MD, Robert D. Stewart, MD, and Gösta B. Pettersson, MD, PhD, \\ Cleveland, Ohio
}



Cor triatriatum dexter (CTD) is an extremely rare congenital cardiac anomaly in which the right atrium (RA) is divided into 2 chambers by a membrane; it is caused by persistence, instead of the usual regression, of the right valve of the sinus venosus and is frequently associated with right-sided cardiac abnormalities. ${ }^{1}$ CTD has varying

From the Department of Thoracic and Cardiovascular Surgery, Heart and Vascular Institute, Cleveland Clinic, Cleveland, Ohio.

Disclosures: Authors have nothing to disclose with regard to commercial support.

Received for publication Nov 11, 2014; accepted for publication Nov 28, 2014; available ahead of print Jan 23, 2015.

Address for reprints: Gösta B. Pettersson, MD, PhD, Department of Thoracic and Cardiovascular Surgery, Cleveland Clinic, 9500 Euclid Ave/Desk J4-1, Cleveland, OH 44195 (E-mail: petterg@ccf.org).

J Thorac Cardiovasc Surg 2015;149:e48-50

$0022-5223 / \$ 36.00$

Copyright (c) 2015 by The American Association for Thoracic Surgery

http://dx.doi.org/10.1016/j.jtcvs.2014.11.078 clinical manifestations, depending on the degree of partitioning or septation of the RA, from completely asymptomatic to severe right-sided heart failure. ${ }^{2-4} \mathrm{We}$ present a case of CTD in a young adult presenting with myocardial infarction and pulmonary embolism who eventually underwent successful surgical excision of the membrane and removal of RA and tricuspid valve thrombus.

\section{CLINICAL SUMMARY}

A 22-year-old woman presented with acute-onset leftsided chest pain and shortness of breath and was diagnosed with a small subsegmental pulmonary embolism and placed on enoxaparin. Lower-extremity Doppler was negative. Coagulation studies, including Factor V Leiden mutation, performed because of her family history of pulmonary embolism, were all negative. Echocardiography revealed severe RA enlargement, a thickened tricuspid valve, and a large atrial septal defect with right-to-left shunt. She had a history of asthma and peripheral cyanosis, and she had suffered an inferior-wall myocardial infarction with
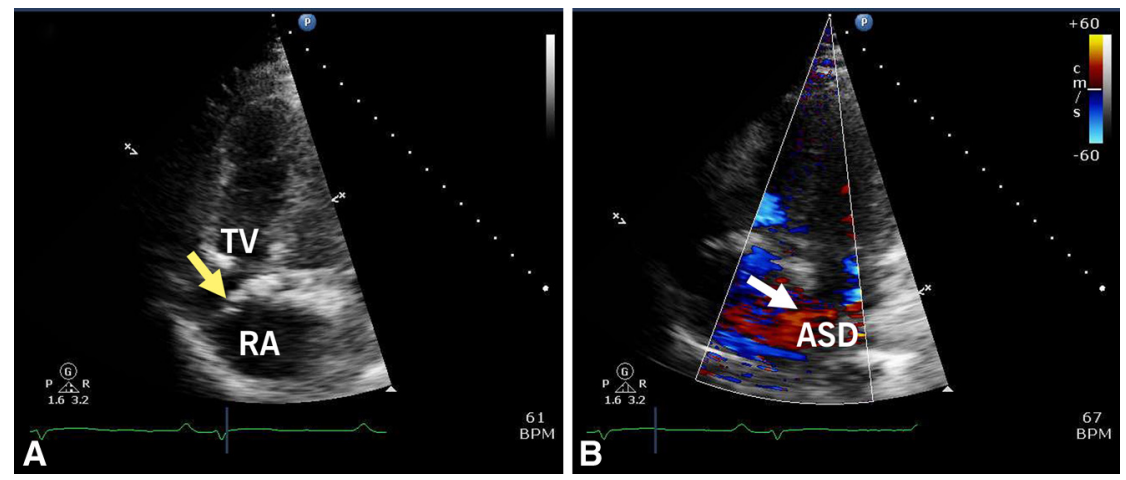

FIGURE 1. Preoperative echocardiogram. A, The thick membrane in the right atrial cavity (yellow arrow) divides the right atrium into 2 chambers. B, Right-to-left flow across the atrial septal defect (white arrow). TV, Tricuspid valve; RA, right atrium; ASD, atrial septal defect. 

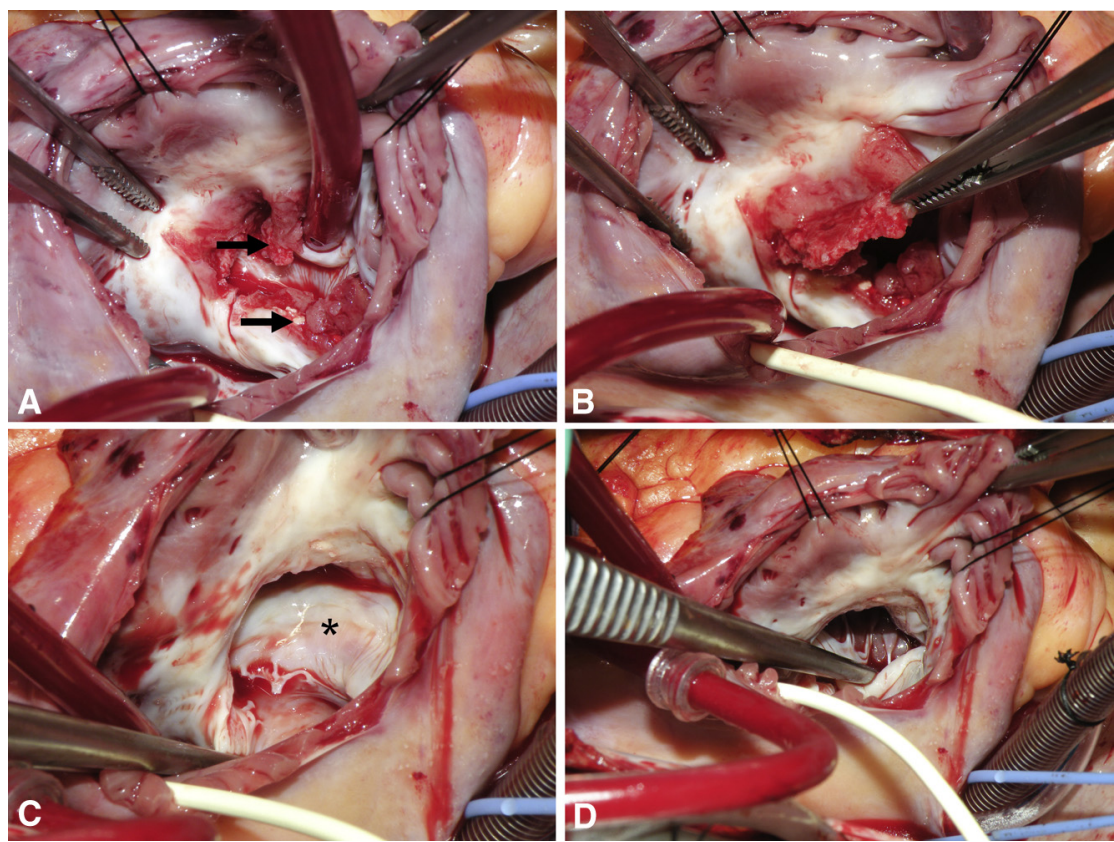

FIGURE 2. Operative photographs of cor triatriatum dexter. A, A thrombus over the thick membrane in the right atrium above the tricuspid valve (arrows). $\mathrm{B}$, Excision of membrane and overlying thrombus. C, Anterior tricuspid annulus and leaflet (asterisk) after excision of the thickened membrane and thrombus. D, Tricuspid valve with normal appearance after complete excision of the supravalvular ridge/ridge and removal of the entire thrombus.

occlusion of the right coronary artery 8 months earlier. At that time, she was immediately postpartum and underwent a balloon angioplasty of the coronary lesion.

Echocardiography (Figure $1, A$ and $B$, and Video 1) showed a very thickened tricuspid valve with moderate stenosis, a possible CTD, and a large fenestrated atrial septal defect. Both ventricles had normal systolic function, but the right ventricle was underfilled. Based on these findings, she was referred for surgery.

After median sternotomy, aortic and bicaval cannulation was performed, and the heart was arrested with antegrade cardioplegia, repeated every 15 minutes. RA exploration revealed a calcified ridge along the tendon of Todaro extending from the inferior vena cava above the coronary sinus to the membranous septum (Figure 2, $A$ and $B$ ). A large thrombotic mass was on top of the ridge, extending onto the anterior tricuspid annulus and the anterior tricuspid valve leaflet (Figure 2,C). The calcified ridge was resected, and all the thrombotic material was peeled off the tricuspid annulus and anterior leaflet, after which the tricuspid valve was essentially normal (Figure 2,D). The atrial septal defect was closed primarily. Because of a high left atrial return during the procedure, the pulmonary artery was also opened to exclude a patent ductus. The postoperative course was uneventful.

\section{DISCUSSION}

Complete persistence of the right valve of the sinus venosus results in separation between the smooth and trabeculated portions of the RA, constituting CTD. ${ }^{1-4}$ The upstream chamber receives superior vena cava and inferior vena cava flows, and the downstream chamber incorporates the right atrial appendage. On echocardiogram, CTD may sometimes be confused with a prominent Eustachian valve. $^{2}$ Echocardiographically, the membrane in CTD is usually seen running from the inferior to the superior vena cava, separating the right atrial appendage and tricuspid valves from the great veins, whereas the Eustachian valve originates from the margin of the inferior vena cava and may show considerable rapid movement within the RA cavity.

Clinical manifestations in patients with CTD are highly variable, depending on the degree of septation or partitioning of the RA. ${ }^{2-4}$ When the septation is mild, the condition is often asymptomatic and detected incidentally during echocardiography or surgery to correct other cardiac abnormalities. More-severe septation can cause rightsided heart failure and elevated central venous pressure, owing to obstruction of the tricuspid valve, right ventricular outflow tract, or inferior vena cava. To the best of our knowledge, this is the first case of CTD in which the patient presented with myocardial infarction and pulmonary embolism. The presence of thrombus on the thick calcified ridge and right-left shunting through the atrial septal defect in our patient was probably responsible for her previous myocardial infarction, and later for the pulmonary embolism. 
Although typically diagnosed in young patients, CTD can present late. ${ }^{2-5}$ Asymptomatic patients are generally not treated unless they are undergoing surgery for other reasons. Surgical resection of the membrane is the treatment of choice for symptomatic patients with significant obstruction, although percutaneous catheter-based disruption of the membrane has been used as an alternative. ${ }^{5}$ However, given the presence of a thick calcified ridge and thrombus in our patient, surgical excision was the preferred treatment modality.

Although CTD is extremely rare, this diagnosis should be considered in patients presenting with symptoms of rightsided heart failure, because it can be easily corrected by surgical excision of the membrane. In our patient, surgery allowed complete understanding of the pathology, removal of the thrombus, and salvage of a normal tricuspid value.

\section{References}

1. Hansing CE, Young WP, Rowe GG. Cor triatriatum dexter. Persistent right sinus venosus valve. Am J Cardiol. 1972;30:559-64.

2. Martinez-Quintana E, Rodriguez-Gonzalez F, Marrero-Santiago H, SantanaMontedeoca J, Lopez-Gude MJ. Cor triatriatum dexter versus prominent Eustachian valve in an adult congenital heart disease patient. Congenit Heart Dis. 2013;8:589-91.

3. Yarrabolu TR, Simpson L, Virani SS, Arora H, Navarijo J, Stainback RF. Cor triatriatum dexter. Tex Heart Inst J. 2007;34:383-5.

4. Caliskan M, Erdogan D, Gullu H, Muderrisoglu H. Cor triatriatum dexter in two adult patients. Int J Cardiovasc Imaging. 2006;22:383-7.

5. Savas V, Samyn J, Schreiber TL, Hauser A, O'Neill WW. Cor triatriatum dexter: recognition and percutaneous transluminal correction. Cathet Cardiovasc Diagn. 1991;23:183-6. 